\title{
Na Busca de Consensos para a Promoção da Coesão Social $O$ percurso profissional de mediadores municipais ciganos
}

\section{Alexandra Castro* Marta Santos*}

\begin{abstract}
Resumo: Partindo da informação empírica recolhida no âmbito da Avaliação do Projecto-Piloto Mediadores Municipais o presente artigo pretende reflectir sobre as potencialidades e constrangimentos da introdução desta figura em contexto de trabalho autárquico e quais os seus impactos na promoção da coesão social.

Movendo-se num território contaminado por estereótipos e preconceitos e por percepções heterogéneas face ao que é ou deve ser a integração de uma minoria específica, a figura do mediador municipal cigano, que se encontra neste âmbito em particular a ser co-construída, tem apresentado algumas lacunas ao nível da sua conceptualização e fundamentação teórica. Estes processos de co-construção da figura de um mediador revelam-nos as percepções e práticas dos vários agentes neste percurso, bem como as formas como se perspectivam o papel da mediação intercultural na promoção da coesão social.

A partir da análise das áreas temáticas de intervenção dos mediadores, dos papéis assumidos por estes e dos tipos de mediação preconizados, bem como da 'leitura' que os vários agentes envolvidos (decisores políticos, técnicos, mediadores e ciganos) tecem face aos resultados alcançados e às expectativas iniciais, sistematizam-se os factores críticos à eficácia das intervenções e promove-se a reflexão em torno dos desafios que se colocam a uma sólida e coerente implementação desta figura a nível autárquico.
\end{abstract}

Palavras-chave: População cigana; Mediadores municipais; Coesão social; Interculturalidade.

\section{Introdução}

Este artigo decorre dos resultados alcançados com a avaliação externa, realizada pelas autoras, ao longo do primeiro ano de implementação do Projecto Mediadores Municipais, lançado pelo Alto Comissariado para a Imigração e Diálogo Intercultural (ACIDI), em Setembro de 2009 e que envolveu, nesta fase piloto quinze autarquias do país ${ }^{1}$. De acordo com o Regulamento do Projecto ${ }^{2}$ considerou-se que “face à importância do envolvimento e intervenção dos mediadores na criação de espaços de partilha e à necessidade de facilitar a proximidade e o diálogo entre as comunidades ciganas e não ciganas (...) impôs-se promover o Projecto-Piloto Mediadores Municipais, com o objectivo de criar sinergias locais, sendo os Municípios os dinamizadores privilegiados." Ainda segundo este documento o projecto “estrutura-se através da colocação de Mediadores Municipais nos serviços das câmaras municipais ou iniciativas promovidas por estas, no âmbito de um programa de formação em contexto de trabalho." Apesar de não constar no Regulamento, ACIDI, através do Centro de Estudos para a Intervenção

\footnotetext{
**Investigadoras do DINÂMIA-CET do ISCTE-IUL.

O Projecto decorreu nos concelhos de Amadora, Aveiro, Beja, Coimbra, Idanha-a-Nova, Lamego, Marinha Grande, Moura, Paredes, Peso da Régua, Seixal, Setúbal, Sines, Sintra, Vidigueira. Estes concelhos encontram-se distribuídos por $1 \bullet$ distritos de Portugal Continental e 4 regiöes. Apesar da Regiāo do Algarve nāo ter visto aprovada nenhuma candidatura (desta região, apenas Vila Real de Santo António apresentou candidatura, no entanto nāo reuniu os requisitos para a sua elegibilidade), existe uma distribuição geográfica relativamente equitativa pelas restantes 4 regiōes.

${ }^{2}$ Disponível em: hıtp://www.ciga-nos.pl/
} 
Social (CESIS), promoveu 90 horas de formação distribuídas por três módulos ${ }^{3}$.

A avaliação externa do Projecto-Piloto Mediadores Municipais incidiu, por um lado, nas dimensões da concepção, operacionalização, execução e impactes do projecto, no sentido de facilitar e promover uma análise mais objectiva, compreensiva e aprofundada não só das problemáticas que se pretendiam resolver, como dos processos adoptados para a sua resolução nas diferentes fases, bem como dos resultados obtidos. Por outro lado, assumiu-se como uma avaliação de acompanhamento, através da elaboração de um conjunto de documentos de apoio à tomada de decisão, permitindo dar recomendações ainda no decorrer do Projecto, através de feedbacks facilitadores de uma melhoria da sua intervenção. Por fim, considerou-se fundamental formatar os resultados para a sua difusão face a intervenções semelhantes e para o alargamento deste projecto a outros municípios.

A metodologia accionada no decorrer da avaliação foi fundamentalmente de carácter intensivo e qualitativo, privilegiando-se o recurso à recolha $\mathrm{e}$ análise documental; à observação directa dos contextos de intervenção dos mediadores; à realização e análise de conteúdo de entrevistas semidirectivas (individuais e colectivas) a autarcas, coordenadores técnicos dos projectos, mediadores e formadores (num total de 49); à dinamização de focus group com destinatários ciganos e com coordenações técnicas e entidades parceiras (num total de 11); à recolha e análise de relatos de experiências de mediação por parte de diferentes intervenientes no projecto (num total de 71). Foi ainda aplicado um balanço de competências final dos mediadores que complementou o realizado pela entidade formadora dos mediadores no início e no final da formação.

A opção por esta estratégia metodológica, apresenta no caso concreto da sua aplicação aos actores implicados neste projecto e no contexto desta avaliação um conjunto de vantagens que importa destacar:
- Permitiu um contacto mais próximo com os contextos onde se desenvolveram os projectos, possibilitando ao mesmo tempo um acompanhamento das formas de implementação e desempenho. Ou seja, as entrevistas realizadas acabaram por abarcar uma dimensão formativa e interventora, não só por terem contribuído para a auto-reflexão dos intervenientes sobre determinados assuntos, como também esclarecer dúvidas e debater opções a tomar sobre determinadas problemáticas;

- Facilitou detectar especificidades das representações sobre a população cigana e formas de intervenção, dificilmente captáveis por respostas categorizadas à partida. Se a presença do gravador nos primeiros minutos da entrevista se revelou, em algumas situações, um obstáculo à produção de um discurso mais fluído, no decorrer da conversa acabou por ser ignorado, possibilitando um discurso mais aberto, franco e menos condicionado por questões políticas ou mesmo éticas;

- Possibilitou confrontar os discursos produzidos com o conhecimento que se tem dos contextos e das problemáticas em presença. Ou seja, a análise das entrevistas não se limitou a uma descrição daquilo que foi recolhido, mas sim a uma interpretação da relação entre o sentido subjectivo das acções realizadas, as práticas efectivas e o contexto social onde decorrem os projectos.

Interessa, de forma breve, dar conta dos contextos de intervenção onde decorreu o Projecto, pois trata-se de um cenário que se apresenta bastante heterogéneo, quer em termos dos territórios ${ }^{4}$ e dimensão da população cigana residente (variando entre 74 elementos na Marinha Grande a 1210 no Seixal), quer no que diz respeito às competências escolares e profissionais dos mediadores. Os modos de implementação dos projectos em cada um dos quinze municípios revelaram-se, pois

\footnotetext{
Os objectivos da formação visaram os seguintes aspectos: construir um entendimento comum sobre o fenómeno da exclusão e inclusão social; aumentar os conhecimentos sobre legislação em diversas áreas, sobre o funcionamento da sociedade e das instituições, de diferentes áreas de actuação e com representação nas redes sociais, sobre programas e medidas sociais; melhorar a capacidade de expressão escrita e oral; fomentar o trabalho em equipa; fornecer elementos para melhorar a capacidade de mediação com diferentes serviços das diversas áreas e de gestão de conflitos; promover a reflexão necessária para um auto-questionamento de certos elementos da "cultura cigana"; dar a conhecer noções de comunicação e estratégias para uma comunicação positiva; aumentar os conhecimentos sobre a utilização das TIC e capacitar para a construção de planos de intervenção pelos mediadores ciganos e para uma boa implementação.

${ }_{4}^{4}$ Tendo em conta as características mais urbanas ou rurais e baseando-nos na tipologia de um estudo, estes territórios apresentam-se bastante diversificados (Castro et al., 2005): rural envelhecido, desqualificado e pouco equipado; rural com concentração demográfica; urbano-industrial difuso; urbano em consolidação, qualificado e equipado; urbano consolidado, qualificado e dinâmico. Esta classificação baseou-se em 15 indicadores repartidos por 4 domínios (dimensão dos lugares/povoamento; dinâmica demográfica; actividades económicas; infraestruturas e equipamentos).
} 
em consonância também bastante diversificados, nomeadamente no que diz respeito às dinâmicas de parceria, como às prioridades de intervenção (mais ou menos centralizadas). Todos estes factores impedem o estabelecimento de rankings em torno do desempenho dos Projectos.

É, ainda, de referir que a população cigana residente nos quinze territórios de intervenção do Projecto totaliza 7362 elementos, ou seja, 14,7\% para um número estimado de 50000 ciganos residentes em Portugal. O peso relativo assumido pelos potenciais destinatários é, assim, bastante relevante, tendo em conta o número de concelhos abrangidos.

\section{A relevância da mediação na reconstrução do laço social: pistas para o seu enquadramento}

As práticas de mediação intercultural têm conhecido, nos últimos anos, um crescente interesse. $\mathrm{O}$ facto de hoje vivermos em sociedades pluriculturais, ao qual não será alheio os mais recentes movimentos migratórios que têm colocado no mesmo espaço pessoas com origens culturais diversas, contribuirá certamente para esta elevada atenção, quer como disciplina ministrada, quer como prática profissional em projectos de intervenção social.

Inicialmente orientada para a resolução de conflitos a mediação foi assumindo cada vez mais um papel de reconstrução de novas formas de coesão social. E tem sido nos interstícios do campo das profissões do social que a mediação se tem afirmado como um novo e inovador recurso (Lemaire e Poitras, 2004 e Demaziére, 2009).

É, precisamente, no contexto de uma sociedade em que grupos, organizações e indivíduos revelam, muitas vezes, incapacidade para viver em conjunto, que Lemaire e Poitras sustentam que a mediação surge, por um lado, como consequência da desagregação do laço social e, por outro, como uma resposta adaptada para reconstruir uma nova forma de coesão social. De acordo com estes autores, as práticas de mediação social e de mediação comunitária revestem-se de bastante interesse, na medida em que constituem tentativas de resposta aos novos problemas sociais, sobretudo, aqueles em que as soluções tradicionais se têm revelado inadequadas (Lemaire e Poitras, 2004:18).

Em Portugal, como noutros países europeus, o aparecimento de um conjunto de experiências piloto de mediação intercultural partiu sobretudo de ONG's, movimentos associativos e de projectos de curta e média duração dando origem, por um lado, a uma diversidade de experiências neste campo e à introdução de inovações, e por outro lado, a um crescente alargamento do âmbito da sua intervenção, passando da gestão e resolução de conflitos para a (re)construção, em sentido amplo, de relações interculturais entre indivíduos e/ou comunidades diferenciadas. É hoje consensual (Freire 2009, Gimenez 2010, Luison e Velastro, 2004) que a mediação vai muito para além da resolução do conflito, protagonizando um projecto de mudança por via da construção de canais de diálogo e de capacitação para a participação nas esferas sociais, políticas e económicas de populações que tendencialmente delas se mantêm afastadas. Este instrumento de intervenção tem-se revelado de grande utilidade em contextos em que à co-presença de universos culturais e simbólicos distintos se aliam situações de precariedade socioeconómica. Nestes contextos de intervenção a mediação assume-se como um projecto mobilizador de «restauração de laços sociais, sustentando modalidades alternativas de gestão das relações sociais, tornando-se um processo comunicacional de transformação do social e uma requalificação das relações sociais» (Oliveira, 2005:26).

As práticas de mediação têm decorrido de forma pouco formalizada, tendo o seu corpus de conteúdos e competências sido normalmente construído em contexto de trabalho e decorrente de uma inserção profissional específica. Esta situação tem contribuído para uma maior visibilidade destas práticas, mas estará também na origem de uma miscigenização de práticas e valores associados. A mediação desenvolve-se, assim, como actividade complementar, situando-se nas fronteiras de actividades já existentes e na periferia de corpos profissionais já reconhecidos (Demaziére, 2009).

Deste modo, a expansão das práticas de mediação intercultural não tem vindo a ser acompanhada de uma sólida fundamentação teórica e conceptual. Neste campo a prática tem estado na dianteira da teoria (Gimenez, 2006, Nuria, 2006). Esta 'urgência prática' conduziu à inexistência de uma reflexão teórica sobre a mediação intercultural o que pode obstaculizar o aproveitamento adequado das suas potencialidades, perdendo-se desta forma, as mais- 
-valias produzidas por um conjunto significativo de projectos que têm contribuído para a construção da figura do mediador.

Existe, contudo, um conjunto de autores - na sua maioria intimamente ligados à prática da mediação e/ou à sua promoção - que têm, nos últimos anos, realizado um exercício de conceptualização da mediação, despoletando alguns debates bastante pertinentes $^{5}$. No entanto, no contexto do presente artigo centrar-nos-emos no alargamento progressivo do âmbito da mediação e da sua dimensão como prática transformadora.

Jean François Six (1990) identifica quatro funções características da mediação distinguindo entre mediação criadora que tem como objectivo criar laços entre pessoas e grupos que serão benéficos a uns e outros; mediação renovadora que permite melhorar as relações existentes entre pessoas ou grupos; mediação preventiva, cujo enfoque se centra na prevenção de um conflito em gestação e a mediação curativa com o intuito de resolver o conflito. Esta sistematização tem como virtude alargar o campo de acção da mediação, inscrevendo-a numa dinâmica de restabelecimento do laço social ou mesmo criação de novas formas de sociabilidade social.

Também Bonafe-Schmitt (1992), no âmbito da mediação comunitária, veio enfatizar o envolvimento voluntário dos indivíduos em causas-situações que os atinjam e, em processos de capacitação para a acção e mudança, aspectos particularmente pertinentes quando estamos perante situações de desigualdade de acesso aos serviços e às oportunidades, promovendo-se a capacitação e favorecendo-se a sua autonomia. Assim, e tal como afirmam Louison e Valastro, «La médiation sociale, tout en soutenant la promotion d'une culture alternative de la gestion des conflits et développant des méthodologies concrètes de gestion de la communication, poursuit une finalité fondamentale: parvenir à une recomposition pacifique des relations humaines» (Louison e Valastro, 2004: 4).

Como contributo para a sustentação de um mo- delo de mediação intercultural Giménez elaborou uma proposta de unificação metodológica recorrendo aos aspectos mais positivos dos principais paradigmas de mediação: modelo de Harvard, modelo transformativo e modelo circular-narrativo ${ }^{6}$. Para Giménez é necessário adaptar criativamente os modelos já existentes na mediação em geral aos contextos multiculturais e à especificidades das relações interétnicas. Assim, propõe como categorias centrais da mediação intercultural o diálogo intercultural, opções de benefício mútuo, revalorização, reconhecimento, legitimação e história alternativa (Gimenez, 2006).

Perante a multiplicidade de factores que estão na origem da conflitualidade interétnica, situar a mediação intercultural, no seu sentido mais amplo, significa assumir como desígnio a melhoria das relações interculturais, através da reconstrução relacional e da promoção da capacidade de agir quer de indivíduos, quer de grupos. Objectivos tanto mais importantes quando estamos a falar de relações marcadas por sistemas e hierarquias de poder configuradas a partir de processos de marginalização e estigmatização.

Chegamos, assim, a uma definição de mediação intercultural bastante abrangente: "modalidade de intervenção de terceiros, em e sobre situações sociais de multiculturalidade significativa, orientada para o reconhecimento do Outro e para a aproximação das partes, para a comunicação e compreensão mútua, para a aprendizagem e o desenvolvimento da convivência, para a regulação de conflitos e de adequação institucional, entre actores sociais ou institucionais etnoculturalmente diferenciados." (Giménez, 1997:142).

\section{As potencialidades da pertença étnica do mediador}

A pertença étnica do mediador tem constituído um dos aspectos mais controversos do debate sobre a mediação intercultural. As posições mais restritas

\footnotetext{
${ }_{5}^{5}$ Nomeadamente a distância verificada entre o consenso teórico em torno do conceito de mediação e as práticas que emergem das iniciativas promovidas por instituições públicas ou privadas, ou a forma como se entende a neutralidade e imparcialidade na mediação (como competência, principio ou método) e a sustentação prática destes atributos.

${ }^{6} \mathrm{O}$ modelo de Harvard (ou método Fischer-Ury) constitui um método de mediação baseado na negociação assistida para a resolução de um conflito. $\mathrm{O}$ modelo transformativo (ou método Bush-Folger) encontra-se centrado na melhoria e transformação das relações humanas. $\mathrm{O}$ acordo é uma consequência, reflexo da melhoria da relação. O conflito constitui uma oportunidade para o fortalecimento do eu e superação dos limites para nos relacionarmos com os outros. O modelo circular-narrativo encontra-se orientado para a modificação da relação. O seu método procura incutir algum caos na ordem "subjectiva", introduzindo a flexibilização das posições e estimulando desta forma a reflexão e a modificação das histórias inicialmente trazidas para a relação.
} 
sobre o âmbito da mediação intercultural defendem claramente que o mediador deve posicionar-se de forma equidistante face às partes envolvidas, como garante da sua posição de neutralidade e imparcialidade e que esta é uma condição sine qua non para se poder falar de mediação. Porém, outros consideram que a neutralidade e imparcialidade constituem competências a accionar nas metodologias de mediação, ou seja, fala-se de 'imparcialidade técnica' Perante contextos de desigualdade e assimetrias no uso e acesso ao poder, há que reflectir sobre a rígida manutenção destas premissas na mediação intercultural, uma vez que os mediadores influenciam e inclusivamente modelam tanto o processo como o resultado substantivo da (re)criação de relação.

No terreno empírico, verificamos que surgiu como consensual para todas as coordenações técnicas e algumas entidades parceiras a vantagem destes mediadores municipais serem recrutados entre as comunidades ciganas locais. Embora em alguns casos se tenha reconhecido alguns inconvenientes desta pertença, as potencialidades tendem a superar largamente os constrangimentos em torno da falta de imparcialidade, de neutralidade ou de reconhecimento perante todas as famílias ciganas residentes em determinado território.

Uma das vantagens apontadas prende-se com os resultados que se conseguem obter em torno de um melhor conhecimento das especificidades culturais, permitindo uma descodificação de códigos e uma melhor comunicação, mas também uma adaptação das estratégias de intervenção aos destinatários ciganos. Alguns municípios identificaram explicitamente como mais-valia esta pertença étnica do mediador por permitir colmatar incapacidades técnicas no diálogo intercultural.

“Acho que é importante ser cigano. E há coisas onde não se pode entrar, que só eles entendem e nada melhor que um mediador cigano." (Coordenação técnica, 22.02.10)

Outra potencialidade enunciada é a facilitação da aproximação, permitindo com maior rapidez e eficácia estabelecer relações de confiança com as famílias destinatárias do projecto.

"O facto de ele estar cá connosco, para a comunidade é um bocado saber que está lá alguém que é nosso e que vai saber dizer que sim ou que não às nossas questões e criou mais coesão entre os serviços e a comunidade" (Coordenação técnica, 02.02.10)
Para alguns municipios a pertença do mediador à comunidade cigana constitui em si mesmo uma estratégia de intervenção junto destas comunidades, uma vez que se julga que a inserção profissional do mediador numa autarquia produzirá uma imagem positiva para a população cigana e não cigana:

"Penso que já foi um grande passo eles verem um membro da sua comunidade cigana instalado na câmara, num gabinete, no meio das técnicas e das pessoas que o acompanham. Assim percebem que há alguém que consegue ter um emprego como as outras pessoas que não são da etnia. $O$ crescimento que ele tiver vai reflectir-se como exemplo na comunidade" (Vereadora, 04.02.10)

Importa chamar a atenção do caso particular de um município, que acabou, no final do primeiro ano, por abandonar o projecto, e onde se observou o desvirtuamento do trabalho do mediador. Neste caso, a principal vantagem apontada pela coordenação técnica e pelo presidente do município foi a capacidade do mediador, por ter maior credibilidade junto das comunidades ciganas, em transmitir melhor as mensagens da autarquia, nomeadamente no que diz respeito ao cumprimento de deveres e obrigações. O papel reservado ao mediador foi preferencialmente o de complementar a intervenção dos técnicos, sobretudo, nas tarefas de controlo social (entrega de notificações de contra-ordenações e dissuasão da utilização de terrenos privados ou públicos para pastagem de animais), impedindo deste logo a procura de consensos entre as partes: população autuada - autarquia e a restauração do diálogo. Este constitui de facto um dos perigos da prática da mediação ao serviço de instituições, tal como Guilaume-Hofnung bem assinalou: "Parfois le recours à la mediation conduit à des délégations inavouées faisant du médiateur un auxiliaire très controlé d'un service public. La médiation assume alors une mission pénale, policière, sécuritaire ou d'assistance qui la parasite et l'instrumentalise." (Guilaume-Hofnung, s/d: 25).

No entanto, alguns municípios, divergindo da maioria, interrogam-se sobre a necessidade da pertença étnica do mediador, argumentando, que a confiança não se encontra garantida a priori por o mediador ser um elemento da população cigana. O importante, advogar, é esta figura ser dotada de certas competências como a comunicação, a empatia e de relação com o outro: 
"Aqui há uma certa concepção de que se for alguém da comunidade já tem ganha essa confiança, o que não é verdade, porque ser da comunidade também pode ser um obstáculo. Não me parece difícil uma pessoa que consegue comunicar, não é preciso um cigano para ganhar a confiança das pessoas" (Coordenação técnica, 22.02.10)

Noutro município, por exemplo, é defendida a ideia de que face ao contexto em que os problemas se colocam é importante o mediador ser cigano, mas qualquer técnico com formação adequada e capacidades de relacionamento interpessoal poderia assumir esse papel:

"Nesta fase em que começa a surgir a figura do mediador é uma mais valia ser um cigano, mas eu julgo que havendo formação e um investimento muito grande por parte de qualquer outra pessoa que consiga fazer a aproximação, porque assim entramos noutra questão, que é só ciganos é que podem trabalhar com ciganos. Eu não sou apologista disso. Mas requer um trabalho muito próximo e um investimento muito próximo" (Adjunta da Vereação, 18.02.10)

\section{A necessária clarificação do papel do mediador}

Os mediadores municipais estão, assim, perante uma difícil gestão dos seus papéis, na medida em que poderão ser confrontados nas suas práticas profissionais, de forma implícita ou explícita, com o desempenho de funções que podem colidir entre si: técnico de intervenção social enquadrado numa instituição versus representantes e defensores dos interesses do seu grupo de pertença.

Sentindo a necessidade de operar uma clara distinção entre $o$ trabalho do mediador e o de técnico de intervenção social, um dos municípios defendeu a importância de clarificar, junto dos destinatários qual a posição do mediador:

"Aqui o que praticamos é isso, eles são facilitadores, mas não partilham as informações relativamente às pessoas, nas anotações em termos de processos, essas informações estão codificadas, é fundamental que não se exponham, nem eles próprios nem as pessoas com quem trabalham. Ao fim deste tempo toda a gente percebeu que eles estão lá para ajudar e que não havia nenhuma intenção da câmara e dos outros de arranjar espiões para os controlar, mas que há ali pessoas que são pagas por fora para ajudar as outras pessoas e que isso não implica nenhuma traição" (Coordenação técnica, 22.02.10)

Esta clarificação assume-se como um aspecto fundamental na medida em que a outorgação de um poder institucional que lhe pode ser conferida como um trabalhador do município constitui-se como um constrangimento não isento de dificuldades na sua gestão: o posicionamento do mediador do lado da administração pública e não entre esta e os destinatários ciganos. Assim, impõe-se uma cuidadosa gestão deste dilema e uma definição clara dos seus limites de intervenção e do seu posicionamento.

Atendendo aos testemunhos recolhidos, o debate e a reflexão conjunta sobre esta matéria, envolvendo em simultâneo os agentes envolvidos (mediadores, técnicos de intervenção social, parceiros e autarcas) seria particularmente proveitoso.

Esta discussão pode ser sustentada em torno da sistematização dos vários papéis que os mediadores assumiram e $o$ tipo de mediação que desenvolveram neste primeiro ano de Projecto (cf. Figura 1). Importa referir que estes papéis não se manifestaram em todos os concelhos e decorreram da especificidade dos contextos, da orientação dada pelas coordenações, da mobilização das competências associadas à mediação, concretamente a sua capacidade de sensibilização e mobilização para a participação da população cigana e para o diálogo com os diferentes destinatários, mas também dos estilos de cada um para fazer a mediação.

Estes papéis remetem, assim, para a diversidade de tipo de mediações que foram postas em prática ao longo de apenas um ano. Concretamente o mediador ao assumir o papel de facilitador no diagnóstico e no planeamento de actividades desenvolve uma mediação avaliativa que passa pelo aprofundamento do conhecimento sobre as comunidades ciganas residentes no território, nomeadamente detectando-se as forças e fraquezas e propondo-se soluções para a intervenção. $\mathrm{O}$ mediador como agente de mudança e de reconstrutor do laço socialdesenvolve sobretudo uma mediação transformativa que procurando a satisfação de necessidades e interesses, valoriza as dimensões de empowerment, reconhecimento, auto-estima, segurança, confiança e autonomia dos actores. Por fim, assumindo-se como reconstrutor 
da capacidade de agirdesenvolve sobretudo uma mediação facilitativa que vê a população cigana como sendo capaz de desenvolver as melhores soluções para os problemas identificados, criando as condições para se estabelecer o diálogo e a participação.

Como podemos perceber as práticas de mediação intercultural desenvolvidas na maioria dos concelhos abrangidos ultrapassaram em muito a dimensão de regulação de conflitos que esteve na origem do aparecimento da mediação profissionalizada, centrando-se no empowerment das populações ciganas residentes nos territórios abrangidos, não só na dimensão individual da mudança, como na dimensão colectiva? .

Figura 1: Papéis assumidos pelos mediadores e tipos de mediação
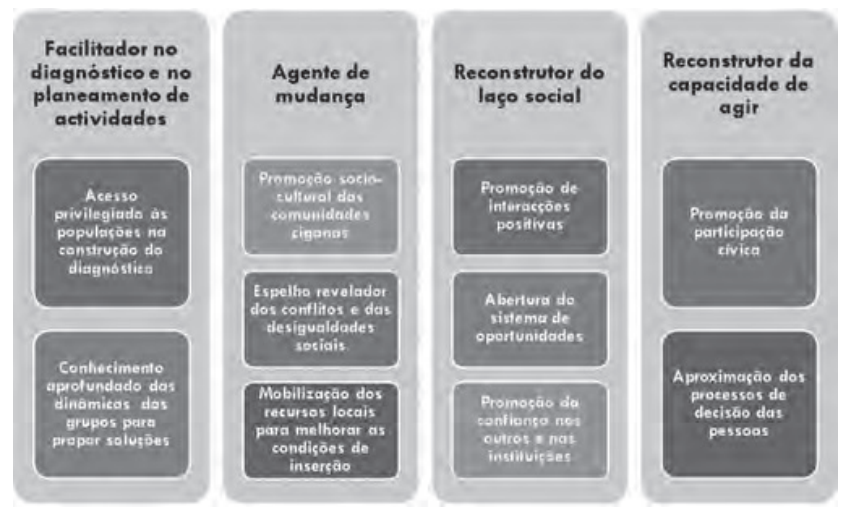

\section{Áreas de actuação privilegiadas na intervenção realizada pelo mediador ${ }^{8}$}

A análise das actividades dos mediadores, ao longo dos doze meses de duração do projecto permitiu aferir a existência de dez áreas de intervenção distintas: Educação, Acção Social, Habitação, Diálogo Intercultural, Diagnóstico, Saúde, Formação do Mediador, Promoção do Projecto, Formação e Emprego, Cidadania.

As áreas de intervenção privilegiadas verificam- -se com maior frequência na esfera da educação (23\% do total das actividades dos mediadores) e no desenvolvimento de intervenções na área da Acção Social (19\%), centradas principalmente no encaminhamento e apoio no acesso aos serviços e direitos sociais. O desenvolvimento de acções no domínio da habitação ${ }^{9}$ surge também, neste panorama geral, com alguma expressão (14\%).

Com uma expressão menor, porém significativa, verifica-se algum investimento em acções de diagnóstico, o que permitiu em alguns concelhos realizar pela primeira vez ou complementar estudos de caracterização da população cigana residente, possibilitando uma maior adequação da intervenção às necessidades e problemáticas identificadas.

Confrontando as áreas de actuação privilegiadas pelos municípios com as áreas problemáticas identificadas nas candidaturas a este Projecto, ou seja, os fundamentos que justificaram a necessidade e interesse dos municípios em aderir a esta iniciativa, verifica-se existir alguma distância entre as necessidades de actuação e as respostas concretas dadas ao nível da actuação do mediador no terreno.

No caso do domínio da habitação e apesar de esta ser uma área problemática para doze dos quinze municípios, a forma como se perspectiva a sua evolução futura ultrapassa largamente os resultados passíveis de alcançar com um projecto desta natureza. Deste modo, o que se verificou é que nos planos de intervenção o domínio de habitação foi eleito como uma área de intervenção para oito dos municípios, mas na prática apenas $14 \%$ das actividades dos mediadores ocorreram neste domínio. Refira-se que alguns dos municípios tinham planeado o início de projectos de realojamento, perspectivando o mediador como recurso no apoio a essas operações, porém, esses projectos não foram ainda concretizados no decurso deste ano.

As baixas qualificações e as dificuldades de inserção no mercado de trabalho constam igualmente entre as principais problemáticas registadas nas candidaturas. Em consonância o emprego e a forma-

\footnotetext{
${ }_{7}$ Entende-se o conceito de empowerment, na perspectiva de Bossé como o desenvolvimento da capacidade de agir, através da articulação entre o se pôr em acção e a disponibilidade de recursos que ela requer (Bossé, 2003).

${ }^{8}$ A aferição das áreas de actividade dos mediadores baseou-se na recolha e sistematização de informação contida em relatórios (formatados pelo ACIDI) que os municípios elaboravam mensalmente. Um dos seus campos era precisamente a descricão de todas as actividades dos mediadores desenvolvidas em cada mês. Refira-se que a presente análise baseia-se na quase totalidade dos relatórios (85\%), uma vez que alguns dos municípios ainda não procederam à totalidade do seu envio, sobretudo, os relativos aos dois últimos meses de execução do Projecto.

${ }^{9}$ Consideraram-se acções ocorridas no domínio da habitação, todas aquelas que decorreram em contextos habitacionais específicos e se destinaram a promover melhores condições de habitabilidade tanto do ponto de vista físico, como social (exemplo: melhoria das relações de vizinhança).
} 
ção profissional constituem uma área de actuação presente em oito planos de intervenção. Contudo, apenas $6 \%$ das actividades dos mediadores são dedicadas à promoção da formação profissional e empregabilidade da população cigana.

No domínio do diálogo intercultural, onde se inscrevem as actividades dedicadas a promover um maior inter-conhecimento e aproximação entre a população cigana e a população não cigana, verificamos existir também um hiato entre a sua consideração como área problemática, as respostas planeadas e as actividades concretizadas.

\section{A estruturalidade de alguns constrangimentos à intervenção}

Interessa, agora, reflectir em torno dos factores, que em alguns territórios, se assumiram como constrangimentos ao desenvolvimento da intervenção do mediador e que de alguma forma estão relacionados com a incidência privilegiada em determinadas áreas de actuação. Dois aspectos têm de ser ressalvados em torno do peso que eles assumem. O primeiro prende-se com a particularidade dos próprios contextos que pode fazer emergir de forma diferenciada estes constrangimentos (ex.: o número e perfil de entidades envolvidas nas actividades, as características e dimensão da população cigana, a experiência de intervenção com a população cigana e com outros grupos vulneráveis por parte das autarquias e de outras instituições locais...). O segundo prende-se com o facto do peso destes constrangimentos não significar a sua transversalidade aos Projectos, nem a determinado perfil profissional dos diferentes intervenientes envolvidos. Eles devem ser lidos como "sinais de alerta", quer para alguns municípios que, dando continuidade a este tipo de intervenção, poderão encontrar as "melhores" soluções para os contornar e, quer para numa segunda fase de candidaturas se procurar que os projectos aprovados não fiquem reféns destes factores.

$\mathrm{Na}$ perspectiva das coordenações técnicas e entidades parceiras os constrangimentos ao desenvolvimento do projecto prenderam-se, sobretudo, com três tipos de factores: i) factores endógenos ao mediador; ii) factores endógenos aos destinatários das acções: iii) factores relacionados com as formas de coordenação, planeamento e implementação das actividades. Considera-se pertinente desmontar o discurso subjacente a estes factores para melhor se compreender o sentido para que remete cada um dos enunciados, relativizando-se aquilo que se pensa ser específico à implementação deste Projecto com questões de ordem mais estrutural, concretamente a falta de clarificação conceptual da própria actividade de mediação; as representações em torno das causalidades associadas aos processos de desigualdade social entre a população cigana e o contexto de articulação interinstitucional dos próprios territórios.

Os factores endógenos ao mediador enunciados remetem claramente para duas fragilidades da actividade de mediação e que se repercutem na implementação concreta deste Projecto, referimo-nos, como anteriormente já mencionado, à falta de clarificação do papel do mediador e das competências a mobilizar.

Na primeira situação constata-se que quando se afirma que o "mediador recusa desempenhar determinados tipos de funções ou de se relacionar com determinadas famílias" não se questiona se ele poderá efectivamente exercer certas tarefas de acordo com o conteúdo funcional da sua profissão e não se reflecte sobre as repercussões que o desempenho de certas tarefas pode ter no trabalho que está a desenvolver ou mesmo na sua vida pessoal. $\mathrm{Na}$ segunda situação, são enunciadas algumas competências que, no entender destes interlocutores, ainda não estão suficientemente trabalhadas, concretamente a sua "desmotivação/incapacidade na promoção e dinamização de algumas acções de sensibilização e de mobilização da população para participar em certas actividades"; a sua "dificuldade em transmitir a mensagem dos técnicos em torno da co-responsabilização social para o acesso aos direitos" e a sua "dificuldade em gerir as expectativas da população face aos tempos de resposta dos serviços, já que a morosidade nas respostas tende para uma descredibilização do mediador".

Algumas considerações devem ser feitas no sentido de se relativizar os enunciados acima descritos. Por um lado, o mediador e, concretamente um mediador municipal cigano, é uma figura em construção, pelo que dificilmente pode dominar todas as competências e habilidades necessárias para se converter num excelente profissional para ambas as partes. Por outro lado, o processo de recrutamento destes mediadores não deve ser descurado. Os critérios mobilizados assumem particular importância num contexto em que os potenciais elementos da 
população cigana disponíveis para integrarem um projecto desta natureza são em número reduzido, nomeadamente com formações especializadas que permitissem o seu recrutamento através de critérios mais objectivos ${ }^{10}$. No contexto deste Projecto e em oito municípios, onde havia mais do que um candidato, os mediadores foram essencialmente recrutados tendo por base os seguintes critérios: conhecimento dos contextos de intervenção (territórios e população); ser do concelho e residir no local de intervenção; percurso e opções de vida; ser pastor da igreja evangélica como sinónimo de credibilidade e conhecimento junto dos serviços e de influência junto das famílias ciganas; nível de experiência de mediação; capacidade de comunicação e motivação; nível de escolaridade; idade. Como se constata, os processos de selecção basearam-se menos nas aprendizagens formais, procurando, sobretudo, identificar o saber-fazer e o saber-ser, de uma forma mais informal e através das experiências biográficas dos candidatos. Recrutar com base em critérios pouco formalizados acaba por ter algumas repercussões ao nível da aceitação do mediador seleccionado, mas também na mobilização de competências para a intervenção que não foram ainda suficientemente exploradas em contexto de formação. Também não é de menosprezar que a base de escolaridade de partida - apenas cinco têm escolaridade igual ou superior ao 9. ${ }^{\circ}$ ano - e a sua jovialidade - onze têm idades compreendidas entre os 20 e os 39 anos - não deveria permitiria ter expectativas muito elevadas face a um desempenho profissional que tende, em algumas situações, a assemelhar-se ao desenvolvido por assistentes sociais.

Os factores endógenos aos destinatários ciganos que foram enunciados remetem claramente para a existência de imagens estereotipadas em torno da população cigana e de uma concepção do sentido da integração que traria mais benefícios se fosse sinónimo de assimilação, ou seja, de adopção progressiva dos padrões sócio-culturais e normativos da sociedade maioritária.

Aquelas imagens traduzem-se em discursos de algumas coordenações técnicas e certas entidades parceiras que afirmam existir: "resistência à integração por parte da população cigana"; "depen- dência da população face ao Rendimento Social de Inserção"; falta de esforço pessoal"; "falta de abertura para a comunicação por parte de alguns agregados"; "falta de interiorização de determinadas regras". Estes discursos tendem para uma adesão acrítica ao pressuposto de que a população cigana residentes nos territórios de intervenção do Projecto assume estas características sem se questionar a possibilidade de diferenciação interna e as causalidades desta situação.

Por outro lado, as estratégias de intervenção que são mobilizadas e o seu impacto reduzido face aos resultados que eram esperados alcançar revelam um fraco questionamento em torno dos constrangimentos, remetendo-se a causa do insucesso para factores endógenos aos destinatários: "desvalorização das temáticas abordadas em acções de sensibilização", "fraco envolvimento das famílias face ao percurso escolar dos seus filhos", "falta de confiança do trabalho das organizações no apoio às populações vulneráveis".

Olhando para os territórios onde decorreu o Projecto um dado não é de menosprezar: em sete concelhos mais de metade da população cigana reside em más condições de habitabilidade, totalizando 1538 indivíduos, ou seja, 87,1\% do total da população cigana em situação de precariedade habitacional no conjunto dos quinze municípios. Esta situação reflecte-se num quadro de vida de grande isolamento e vulnerabilidade social que não facilitou, ao longo dos anos, a possibilidade de encontro, nem o conhecimento entre os diferentes actores em presença num território, promovendo-se do lado do grupo sociocultural maioritário a difusão de imagens estereotipadas, tendencialmente negativas e homogeneizantes e, do lado do grupo minoritário a tendência para se desenvolverem posições de fechamento, defesa ou ataque.

De facto, a situação de desvantagem social vivenciada muitas vezes ao longo de várias gerações e a não abertura do sistema de oportunidades acaba por gerar sentimentos de desconfiança relativamente à capacidade/vontade que os organismos públicos podem ter na promoção da inclusão social. Estes sentimentos generalizados de desconfiança não devem, no entanto, ser encarados como um traço

\footnotetext{
${ }^{10}$ De acordo com o Regulamento que enquadra o Projecto, as pessoas indicadas nas candidaturas deveriam ter no mínimo o $4 .{ }^{\circ}$ ano de escolaridade do Ensino Básico, serem objecto de confiança a nível local pelos diferentes grupos socioculturais, terem capacidade comunicativa e facilidade de criar empatia e consensos.
} 
da população cigana. Nicolas Duvoux (2010) referencia uma obra de Jean Futros, psiquiatra francês que trabalha os resultados do ponto de vista da individuação dos sujeitos, onde se refere que as pessoas em situação de vulnerabilidade social tendem a perder o que apelida de três confianças: i) a confiança em si, ii) a confiança nos outros, iii) a confiança no futuro. De facto, a perda de confiança nas instituições e nas suas capacidades para projectarem um melhor futuro para as suas vidas tende a gerar conflitos como forma de reivindicar a mudança ou reflectir a convivência entre pessoas com códigos culturais distintos. A interpretação das intenções das pessoas envolvidas nestes processos de interacção nem sempre é clara, resultado de um certo desconhecimento do modo de funcionamento dos grupos e da grande dificuldade em se distinguir no comportamento do outro o que é efectivamente da ordem da agressão ou da intimidação.

Quando pensamos nas famílias ciganas e nos seus contextos de socialização, normalmente de grande vulnerabilidade e onde predominam sociabilidades intrafamiliares, facilmente se constata que os diversos saber-fazer (comportamentos que modelam as interacções quotidianas em público: normas de conduta, regras de conveniência, formas de cortesia) e dever-fazer (ética que prescreve os comportamentos possíveis e desejáveis e os limites a observar de acordo com o código de civilidade) ${ }^{11}$ se regem por diferentes códigos relativamente ao que está instituído entre uma maioria melhor posicionada socialmente e com outros códigos culturais e modos de vida. Alguns dos discursos recolhidos tendem, assim, a associar a civilidade à urbanidade, ou seja, um comportamento "urbano" tende a corresponder a uma atitude de "urbanidade". Urbanidade e "civilidade" ficam, pois, situadas na esfera de uma normatividade culturalmente aceite, ainda que numa base socialmente discriminada (Ferreira, 2000).

"Há trinta anos que há famílias realojadas em bairros sociais, mas nunca deu resultado como era suposto. No primeiro bairro ainda há problemas, ainda há pouco tempo houve problemas com uma vizinha não-cigana, de agressões de ambas as partes, ameaças de morte, os lixos, preservação dos prédios, tudo, não é só o facto de o bairro estar mais afastado da malha urbana que dificulta a intervenção. Os nossos ciganos são muito rurais..." (Coordenação técnica, 18.02.10)

"A maior parte deles vive num bairro da câmara. E temos vinte famílias de etnia cigana, não são muitos mas eles apoderam-se de tal forma do espaço exterior que quem chega ao bairro pensa que o bairro é deles ao nível do estacionamento, do lazer, apoderam-se muito." (Coordenação técnica, 23.02.10)

"Como é que se integra quem não quer ser integrado? Porque eles também já perceberam que não estando integrados e tendo esta postura que lhes tem dado bons resultados, porque protestam e a comunidade maioritária dá." (Presidente de Câmara, 17.02.10)

Parece, assim, ficar esquecido que a urbanidade é uma troca entre grupos heterogéneos com interesses parcialmente convergentes e com referências culturais diferentes. No entanto, o problema central para a comunicação não é só o desconhecimento, mas também a tradução dos conteúdos da interacção, ou seja, a incompreensão manifesta muitas vezes uma falta de tradução e a impossibilidade de elaborar um compromisso de coexistência, pela dificuldade de transpor os códigos culturais de leitura da vida social e da relação entre certos dispositivos materiais e certos traços culturais (ex.: relação privado público). É neste sentido que Jean Remy alerta para não ser necessário evitar toda a relação conflitual, pois conduz a uma redução progressiva da comunicação. Muitas vezes é necessário que existam intermediários que permitam gerir conflitos e fazer as traduções necessárias (Remy, 1998: 178).

Ao longo da história da presença dos ciganos em Portugal assistiu-se ao desenvolvimento de estratégias de luta contra a alteridade sem que, no entanto, se conseguisse alcançar o tão desejado processo de assimilação $^{12}$. De facto, e apoiando-nos no título de um artigo de Moscovici e Perez (1999) o que se verificou foi "a extraordinária resistência das minorias à pressão das maiorias" com consequências nos processos de percepção sobre as causalidades associadas às situações de pobreza e exclusão social.

\footnotetext{
11 Apoiamo-nos aqui nas definições dadas por Lévy, 1997: 24.

${ }^{12}$ Ver, entre outros, a respeito da presença dos ciganos em Portugal Coelho (1995 [1892)], Nunes (1981), Costa (1991), Costa (1993, 1999), Pinto (2000), Mendes (2005).
} 
Estes autores ao analisarem o processo psicossocial desencadeado por esta resistência constatam, por um lado, que os não ciganos usam as estratégias de conversão que conhecem e, ao verificarem que não resultam no caso dos ciganos, tentam resolver este conflito sociocognitivo representando os ciganos como um grupo com uma 'natureza' diferente da sua, acentuando as representações que maximizam as diferenças. Por outro lado, as estratégias de conversão reforçam a identidade e a autonomia da minoria, que se representa como grupo ameaçado e estrangeiro, face a um grupo hegemónico e ameaçador, em que qualquer compromisso e concessão é uma ameaça à sua existência. Os resultados mostram por um lado, "a persistência e sobretudo o efeito negativo da tendência para incriminar e imputar às minorias a responsabilidade daquilo que lhes acontece; por outro, ilustram a recusa implícita, por parte da maioria, em aceitar a responsabilidade ou em se sentir culpada pelas perseguições e discriminação." (Moscovici e Perez, 1999:119).

"Algumas entidades têm uma aversão aos ciganos e até estamos a pensar em acções de sensibilização junto destes serviços e das pessoas que estão no atendimento" (Coordenação técnica, 22.02.10)

A forma como a sociedade maioritária consolidou os estereótipos e tende a ver a integração como sinónimo de assimilação são, pois, fenómenos muito resistentes à mudança e exigem acções de sensibilização onde todos devem estar implicados para encontrar as melhores soluções. Como alerta Machado, ainda que a redução dos contrastes sociais de minorias desfavorecidas seja fundamental para se poder falar de integração, o mesmo não se passa no que respeita aos contrastes culturais, pois integração não é sinónimo de homogeneidade cultural, ou seja, integração e diversidade cultural são compatíveis. Mas a integração de uma minoria no que respeita ao eixo cultural da etnicidade passa por uma orientação "intensa, regular e diversificada" das suas sociabilidades com a sociedade envolvente (Machado, 2002: 68).

Chegamos, por fim, ao terceiro e último factor que tende a condicionar a eficácia da intervenção e que remete, essencialmente, para a fraca dinâmica de parceria existente em alguns territórios.

Apesar de ao longo dos últimos se ter assistido a uma territorialização das políticas públicas, através da descentralização de meios técnicos e humanos e pela mobilização e envolvimento de distintas entidades que, actuando nas mais diversas áreas, poderiam de forma mais global e eficaz responder às situações de pobreza e exclusão de indivíduos e famílias, em alguns territórios do Projecto este desígnio político parece ainda não ter sido alcançado. A fraca dinâmica de parceria evidenciada repercutiu-se ao nível da falta de resposta das entidades locais para articular a intervenção com o mediador municipal, mas também na fraca mobilização de recursos endógenos ao território que facilitariam a promoção de percursos de inserção mais eficazes. Foi possível apurar em alguns concelhos a existência de práticas institucionais marcadas pelo fechamento sobre si próprias que impedem a promoção de dinâmicas de parceria e comprometem a mobilização concertada dos recursos disponíveis a nível local ou desvirtuando-se a filosofia de determinadas medidas. É o caso, por exemplo, da não participação de algumas entidades com responsabilidades no percurso de inserção de jovens nos Núcleos Executivos do RSI.

"Os ganhos da presença do mediador só podem ser equacionados se os serviços e instituições trabalharem em parceria" (Mediadora, 8.09.10)

"Depois da apresentação do mediador era esperado que as entidades solicitassem a participação do mediador para facilitar na educação, saúde, mas os parceiros não estavam tão receptivos como seria desejável. Alguns ainda não aceitaram como deveriam, ainda não o valorizam, ainda não tem aquela visibilidade que seria desejável" (Coordenação técnica, 7.09.10)

Constata-se, assim, que as contradições na mobilização dos recursos existentes e nas modalidades que assume a administração de determinadas medidas, programas e projectos tendem a não favorecer "as coordenações horizontais entre as entidades locais, nem formas de co-responsabilidade e governabilidade a vários níveis entre instituições ordenadas verticalmente" (Vitale, 2009: 67).

\section{Factores críticos de sucesso e efeitos do Projecto: contributos para a inovação social}

Abordar os factores favoráveis que contribuíram para a eficácia da intervenção do mediador, produ- 
zindo um conjunto de impactes a nível local que reforçam os seus níveis de coesão social é inseparável das motivações que presidiram a estas autarquias candidatarem-se a um projecto desta natureza e da forma como, globalmente, representaram o(s) "problema(s) em torno da população cigana" nos seus territórios.

A análise das candidaturas apresentadas permitiu evidenciar que a configuração do problema se centra nas dificuldades de acesso a direitos fundamentais, como a habitação, a educação e o emprego e formação profissional, apontando-se como causas a este bloqueio diferentes problemáticas em torno da forma que assume a coexistência inter-étnica nos territórios, concretamente:

- Os estereótipos e a pressão da opinião pública a reforçar as distâncias culturais;

- As relações mútuas de desconfiança que se operam no contacto com as instituições;

- O desconhecimento de algumas especificidades da população cigana por parte dos agentes de intervenção a condicionar o diálogo;

- $\mathrm{O}$ fechamento social, a resistência à mudança e à definição de projectos de vida por parte da população cigana.

Configurar o problema desta forma, dar-lhe visibilidade pública e encontrar as soluções mais ajustadas são factores que, por si só, traduzem uma novidade no tratamento desta problemática a nível local. Isto vem assim contrariar duas tendências que se têm registado em Portugal: por um lado, o peso que assume a opinião pública e a posição de alguns actores políticos na inviabilização deste tipo de iniciativas e, por outro, um discurso técnico-político que enfatiza a explicação das desigualdades sociais em torno de comportamentos individuais ou grupais, ignorando os problemas de carácter mais estrutural que lhe estão subjacentes.

As 24 autarquias que se candidataram ao Projecto e as 15 que tiveram a possibilidade de ingressar, nesta primeira fase, pensaram, assim, encontrar na mediação uma via possível para a resolução dos problemas diagnosticados. De salientar, que os projectos implementados acabaram por superar largamente as expectativas inicias, nomeadamente em termos dos impactes alcançados em torno da coesão social dos seus territórios, encarada esta em três dimensões fundamentais: participação nos processos de decisão; reactivação das interacções baseadas na confiança e na reciprocidade; reforço da ideia do bem comum, da partilha de valores, do sentido de pertença e de solidariedade social (Helly et al., 2003: 7).

Mas para a obtenção destes efeitos positivos, como se verá já adiante de forma mais detalhada, convém ressaltar os seis factores chave que condicionaram favoravelmente a eficácia da intervenção dos mediadores:

- Perfil de competências dos mediadores. As capacidades de comunicação, de articulação interinstitucional, de mobilização da população cigana, de negociação, mas também a sua assertividade, adaptabilidade às circunstâncias, persistência, dinamismo e disponibilidade permitiram desenvolver um trabalho continuado, sistemático e próximo dos destinatários.

- Dinâmica de parceria e o perfil dos profissionais. A existência de parcerias e as modalidades assumidas nas suas dinâmicas constituem um factor favorável à intervenção dos mediadores, não só pelo envolvimento de um maior número de entidades permitir um compromisso mais efectivo de diversos actores em torno de um mesmo objectivo, como também facilitar a disseminação dos resultados alcançados a nível intra e interinstitucional.

- Relação de confiança entre a população cigana e o mediador. A identificação positiva com o mediador por parte da população cigana e um conhecimento prévio do mediador relativamente às problemáticas da população-alvo assumem-se como factores indispensáveis para o estabelecimento de relações empáticas e de confiança indispensáveis nos processos de negociação de percursos de inserção ${ }^{13}$ e na promoção do acesso aos recursos.

- Visibilidade da presença do mediador junto da(s) equipa(s) técnicas. O mediador estar enquadrado no seu exercício profissional junto de outros profissionais da autarquia favoreceu o reconhecimento do seu papel tanto por ciganos como por não ciganos, possibilitou um maior desenvolvimento pessoal e profissional do mediador e estimulou o

\footnotetext{
13 Entende-se aqui a inserção como o "duplo movimento que leva, por um lado, as pessoas, as famílias e os grupos em situação de exclusão e de pobreza a iniciar processos que lhes permitam o acesso aos direitos de cidadania e à participação social e, por outro lado, as instituições a oferecer a essas pessoas, famílias e grupos reais oportunidades de iniciar esses processos, disponibilizando-lhes os meios, dando-lhes apoio e criando os lugares sociais onde se possam colocar" (Capucha et al., 1998: 25)
} 
seu envolvimento no planeamento e execução das actividades.

- Participação na concepção e planeamento das actividades. $\mathrm{O}$ envolvimento do mediador no planeamento da intervenção e na definição de formas de actuação mais pontuais, para além de ter incutido maiores níveis de responsabilização na execução das actividades e de se tornarem momentos importantes de formação em contexto de trabalho, permitiu uma intervenção mais ajustada ao perfil dos beneficiários.

- A existência de outros mediadores a actuar nos territórios concelhios ou a designação de representantes das comunidades ciganas locais torna a intervenção mais facilitada, sobretudo, em concelhos com maior número de população cigana ou em territórios de maior dimensão, promovendo também a participação das comunidades ciganas e a troca de experiências entre mediadores.

Os efeitos alcançados com o projecto revelam, na sua grande maioria, terem ido ao encontro das expectativas iniciais que foram enunciadas quer pelo ACIDI, quer pelas coordenações técnicas, quer por elementos dos executivos camarários e também pelos próprios mediadores. Existem, no entanto, algumas nuances que importa salientar quer por terem ficado ainda aquém das expectativas, quer por as terem superado.

Um dos efeitos, reconhecidamente ainda não alcançado como seria desejado e que necessita de um maior investimento ao nível dos planos de intervenção, apelando à criatividade de todos para a implementação de acções na próxima fase do Projecto, prende-se com o combate às imagens estereotipadas e homogeneizantes que recaem sobre população cigana. No entanto, a simples presença do mediador a trabalhar no município, a forma como assumiu as suas responsabilidades e a imagem que conseguiu transmitir permitiram promover uma maior compreensão e respeito das diferenças culturais, não só ao nível dos serviços autárquicos, através do alargamento progressivo da intervenção do mediador a outras entidades e serviços das câmaras municipais, mas também por se ter registado uma maior sensibilização das entidades locais para a figura do mediador e o reconhecimento da existência de mais um recurso entre as entidades locais.

"O importante é as pessoas saberem que há uma pessoa cigana a trabalhar com a autarquia, a questão da visibilidade positiva" (Coordenação técnica, 14.01.01)

"Mexeu sempre positiva ou negativamente com a população, principalmente com os técnicos de outras instituições habituarem-se a esta figura" (Coordenação técnica, 17.02.10)

Por outro lado, os efeitos que se prendem com o tipo e número de percursos de inserção que foi possível desencadear, graças à facilitação da comunicação, às relações positivas de confiança estabelecidas entre técnicos-população, à dinâmica positiva do trabalho inter-institucional foram largamente superados face às expectativas inicialmente enunciadas pelas coordenação técnica e por presidentes ou vereadores autárquicos.

Este efeito ao nível dos percursos de inserção é indissociável dos impactes do Projecto em torno do aprofundamento do conhecimento sobre as comunidades ciganas. Através de um diagnóstico mais rigoroso foi, assim, possível delinear estratégias e metodologias de actuação mais adaptadas aos problemas/necessidades, onde muitas vezes foi necessário mobilizar mais recursos para a intervenção, e também mais diversificados e facilitadores dos percursos de inserção. Apenas num ano, foi possível constatar os efeitos positivos nestes percursos, onde se destaca, a título de exemplo, os contratos de arrendamento e de trabalho por conta de outrem celebrados, a maior mobilização da população cigana na procura de emprego, um grupo de mulheres que concluiu o $4 .^{\circ}$ ano, a inscrição de crianças no pré-escolar e a participação de crianças em actividades extra escolares. Trata-se, pois, de resultados que revelam o tratamento individual das situações e onde se reconhece a especificidade de cada um dos destinatários.

Surge, assim, um efeito possível ao nível da intervenção, onde em dois concelhos foi possível promover estratégias de intervenção supra-concelhia entre mediadores e dar resposta a solicitações de outros territórios, facilitando a satisfação de necessidades e expectativas da população cigana e incrementando a solidariedade entre territórios.

Mas aqueles percursos de inserção também se tornaram possíveis por se ter fomentado uma comunicação eficiente e adaptada, facilitadora da aproximação aos recursos, serviços e equipamentos e de estímulo à participação cívica. De facto, o mediador e outros ciganos residentes nos concelhos do 
Projecto passaram, por um lado, a ter uma voz mais activa quer na identificação dos seus problemas e necessidades, quer nas soluções que poderiam ser postas em prática para a sua satisfação. Por outro lado, sentiram-se mais próximos dos processos de decisão, compreendendo melhor os seus mecanismos e potenciando a co-responsabilidade social.

"Nós sentimo-nos mais livres por ele estar no sítio onde está. Quando nós temos uma dificuldade vamos ter com ele e ele tenta explicar e tenta levar-nos ao sítio que nós temos que ir. E por isso nós sentimo-nos felizes porque é uma coisa boa para todos nós e para a inclusão dos nossos filhos e também de nós próprios." (Destinatária cigana)

"Nós antes tínhamos mais complexos que nos rejeitássemos. E às vezes nós íamos, dizia-nos que sim e depois não se via nada. E assim já é totalmente diferente." (Destinatário cigano)

"Antigamente se calhava olhavam para nós e diziam: "Ali vai o cigano». Agora as pessoas pensam: Já há ciganos na Câmara, já há ciganos na junta e as pessoas começam a misturar-se umas com as outras e isso é bom. (Destinatária cigana)

Também não é de menosprezar os efeitos ao nível dos percursos de vida dos próprios mediadores. Para cerca de metade dos mediadores este projecto assumiu-se como a sua primeira experiência de trabalho por conta de outrem, possibilitando a desconstrução de estereótipos relativos ao descrédito da integração e de construção de uma imagem de referência entre ciganos e não ciganos. O perfil social e profissional destes profissionais representou, ainda, uma mais-valia ao nível do apoio à intervenção de outros mediadores, disseminando-se práticas e experiências de intervenção.

O projecto permitiu, também, a alguns municípios dar continuidade a intervenções iniciadas no âmbito de outras iniciativas. Para a maioria dos municípios este Projecto é mais um em que a população cigana está entre os seus destinatários, o que sugere a criação de grupos de reflexão para discutir o conjunto de intervenções já desencadeadas, no sentido de se incutir inovação social aos processos e evitar desenvolver acções que já revelaram não ter o efeito desejado.

\section{Algumas pistas para reflexão}

Os resultados aqui apresentados em torno do Projecto Mediadores Municipais fazem ressaltar alguns elementos de reflexão.

Desde logo, tratando-se de um projecto de mediação intercultural promovido pelos municípios - órgãos da administração pública com um leque variado de competências de actuação a nível local - interessa reflectir sobre o grau de especialização que importa reter para garantir maiores níveis de eficácia da intervenção. Como se constatou, a diversidade de áreas de intervenção dos mediadores vai ao encontro das competências dos municípios como estabelecidas na Lei n. ${ }^{\circ}$ 159/99, de 14 de Setembro. Se o potencial associado a esta heterogeneidade de domínios de actuação tem efeitos indiscutíveis em torno da mobilização concertada dos recursos locais, da visibilidade da sua actuação e da probabilidade de continuidade do trabalho desenvolvido, existe, no entanto, um conjunto de factores em discussão que se prendem com a eventual dispersão da sua actuação, dificultando a obtenção de resultados mais imediatos; e com a menor probabilidade de especialização profissional para estes mediadores, como acontece no caso do mediador escolar ou do mediador de saúde.

Por outro lado, para além das práticas de mediação em contextos institucionais serem muito recentes, o mediador municipal ainda o é mais, remetendo-se para uma figura em processo de construção colectiva. Presentemente a sua acepção é bastante heterogénea, bem como as funções que pode e deve assumir o que resulta na multiplicidade de solicitações e de recurso a metodologias variadas. $\mathrm{O}$ futuro dos mediadores municipais pode encontrar alguns obstáculos ao nível do seu enquadramento profissional face aos quadros de pessoal existentes nas autarquias e às formas de contratação pública. Para se legitimar o papel do mediador não será apenas necessário enfatizar politicamente a necessária relevância e utilidade social da mediação, aliás, já assumida no âmbito de outros Programas em curso, como o Escolhas. A responsabilidade do reconhecimento profissional da actividade de mediação está também dependente das acções que enquadram estes profissionais e também da própria mobilização dos mediadores para fazerem fortalecer a sua identidade profissional. Trata-se, no fundo, de um 
esforço de colaboração para o estabelecimento do conjunto de competências pessoais e profissionais que possibilitem a regulamentação do seu estatuto.

A promoção de uma comunidade de prática entre os mediadores poderia ser um dos primeiros passos a dar neste sentido. Esta comunidade de prática poderia assumir dois vectores fundamentais: por um lado, os encontros regulares entre mediadores municipais assumir-se-iam como importantes momentos de aprendizagem colectiva, onde a troca de experiências, a diversidade de formações em presença e de enraizamentos profissionais seriam factores importantes para tornar a sua acção mais eficaz. Por outro lado, estes momentos constituir-se-iam como formas de organização e mobilização colectiva, no sentido de fazerem valer saberes e competências específicos, delimitando-se, assim, o campo profissional e fortalecendo-se a coesão e autonomia de um conjunto de profissionais, cuja actuação no âmbito autárquico apresenta especificidades.

Por fim, e dados os constrangimentos de carácter mais estrutural que tendem a condicionar a eficácia da intervenção dos mediadores, importa reflectir em conteúdos formativos em torno de temáticas como a integração social e a gestão das diferenças, a pobreza e exclusão social e a mediação intercultural(o que é, como se faz, e os seus limites) e que consigam abranger o maior número possível de actores, desde técnicos de diferentes áreas profissionais a autarcas e decisores políticos. Como bem relembra Gimenez, «Se a educação intercultural ficar reduzida aos grupos com problemas, ao grupo a compensar, ao grupo minoritário, será um fracasso total... O verdadeiro desafio da educação intercultural é a cultura maioritária, somos nós» (Giménez 1993 cit em Gimenez 2010: 21).

As experiências realizadas durante este ano, em geral, revelam ser muito promissoras quanto à capacidade de se gerir eficazmente a integração sociocultural das comunidades ciganas. No entanto, existe o perigo de se considerar o mediador como a panaceia salvadora, à qual vamos atribuindo responsabilidades que recaem, sobretudo, na própria sociedade. $\mathrm{O}$ mediador poderá ser um agente de mudança fundamental, mas não deve ser encarado como um substituto do processo de construção do diálogo intercultural. 


\section{Bibliografia citada}

BONAFE-SCHMITT J.-P., (1992), La médiation: une justice douce, Paris, Syros-Alternatives.

BOSSÉ, Y. (2003), “De «l'habilitation» au «pouvoir d'agir»: vers une appréhension plus circonscrite de la notion d'empowerment", Nouvelle Pratique Social, n. ${ }^{\circ} 16$, pp. 30-51.

BRANCO, Francisco (2009), "Acção Social, Individuação e Cidadania", Cidades, Comunidades e Territórios, n. ${ }^{\circ} 17$, Lisboa, CET/ISCTE, pp. 81-91

CALVET, Núria LLevot (2006), "Prospectiva e Retrospectiva da Mediação Intercultural da Catalunha", Portularia, Vol VI, n. ${ }^{\circ} 1$, Universidad de Huelva, pp. 7-16.

CAPUCHA, Luís et al. (1998), Grupos desfavorecidos face ao emprego - Tipologias e Quadro Básico de Medidas Recomendáveis, Lisboa, Observatório do Emprego Formação Profissional.

CASTRO. Alexandra; MARQUES, Ana Sofia (2005), Tipificação das situações de exclusão em Portugal Continental, ISS, http://www.seg-social.pt/.

COELHO, Adolfo (1995) [1892], Os Ciganos em Portugal. Com um estudo sobre o Calão, Lisboa, Edições D. Quixote.

COSTA, Eduardo Maia (1991), "Comentários do código do processo penal - nómadas ou ... ciganos?", Revista do Ministério Público, n. ${ }^{\circ} 46$, Ano $12 .^{\circ}$, pp. 163-178.

COSTA, Maria Elisa Lopes (1993), “O povo Cigano em Portugal: contributo para o seu conhecimento", Escola e Sociedade Multicultural. Lisboa: Ministério da Educação, Secretariado Coordenador de Programas de Educação Multicultural, pp. 91-96.

COSTA, Maria Elisa Lopes (1999), “O povo cigano e o espaço da colonização portuguesa - que contributos?", António Gómez Alfaro, Elisa Maria Lopes da Costa \& Sharon Sillers Floate (Orgs.), Ciganos e degredos. Os casos de Espanha, Portugal e Inglaterra, Sécs. XVI-XIX. Lisboa: Colecção Interface, pp. 49-91.

DEMAZIÉRE, Didier (2009), "Les figures de la reconnaissance profissionnelle de la médiation socioéducative", Actas do Seminário Mediação Socioeducativa: Contextos e Actores, Braga: Universidade do Minho-CIEd.

DUVOUX, Nicolas (2010), Un syndrome de la précarité, disponível em http://www.laviedesidees.fr/IMG/pdf/20091217_autoexclusion.pdf

FERREIRA, Vítor Matias (2000), "Cidade e democracia. Ambiente, património e espaço público", Cidades. Comunidades e Territórios, n. ${ }^{\circ}$ 1, Lisboa, Centro de Estudos Territoriais, pp. 9-35.

FREIRE, Isabel; MOREIRA, Maria Alfredo; SILVA, Ana Maria; CAETANO, Ana Paula (2009), "Contextos e Práticas de Mediação Socioeducativa em Portugal" Actas do Seminário Mediação Socioeducativa: Contextos e Actores, Braga: Universidade do Minho-CIEd.

FUNDACIÓN SECRETARIADO GITANO (2007), "Retos en los contextos multiculturales. Competencias interculturales y reolución de conflictos", Serie de Materiales de Trabajo, n" 32, Madrid, FSG.

GARCÍA CASTAÑO, F., RUIZ-MATAS, Cristina (2006), "Mediacion Intercultural en Sociedades Multiculturales: Hacia una nueva conceptualización", Portularia, n. ${ }^{\circ} 6$ Granada, Universidad de Granada pp. 79-90.
GARCÍA CASTAÑO, F., GRANADOS MARTÍNEZ, Antolín, MARTÍNEZ CHICHÓN, Raquel (2006), "Perfil des Mediador y Mediadora Intercultural", Portularia, n. ${ }^{\circ} 6$ Granada, Universidad de Granada pp. 189-243.

GIMÉNEZ ROMERO, Carlos (1997), “La Naturaleza de la Mediacion Intercultural", Revista Migraciones, $\mathrm{n}^{\circ} 2$, Instituto Universitário de Migraciones, Madrid, Universidad Ponticifia de Comillas, pp. 125-159.

GIMÉNEZ ROMERO, Carlos (2006), "Modelos de Mediation y su aplicación en mediación intercultural”, GARCIA CASTAÑO, F (org), Lecturas para Médiación Intercultural: comprendiendo y construyendo la mediación intercultural, Portularia, n. ${ }^{\circ} 6$ Granada, Universidad de Granada, pp.115-143.

GIMÉNEZ ROMERO, Carlos (2010), "Interculturalidade e Mediação", Cadernos de Apoio à Formação, n. ${ }^{\circ}$ 4, Lisboa, ACIDI.

GUILLAUME-HOFNUNG, Michéle (s/d), "Le concept de médiation et l'urgence théorique", Cahiers du Cremoc, 35www. cremoc.org/articles/medhofnung.pdf.

BLANES, Ruy Llera (2008), Os Aleluias - ciganos evangélicos e música, Lisboa, Imprensa de Ciências Sociais.

HELLY, Denise; BARSKY, Robert F; FOXEN, P. (2003), Social cohesion and cultural plurality, Quebec, Les classiques des sciences socials. Disponível em: http://classiques.uqac.ca/

LEMAIRE, Élise, POITRAS, Jean (2004), "La construction des rapports sociaux comme l'un des objectifs des dispositifs de médiation", Esprit Critique, Vol. 06, n. ${ }^{\circ}$ 3, pp. 17-29.

LEVY, Albert (1997), Explorer l'espace public, Laboratoire Théorie des Mutations Urbaines en Pays Développes, Institut Français d'Urbanisme, Marne-La-Vallée, Texto Policopiado.

LUISON, Lucio, VALASTRO, Orazio Maria (2004), “Du processus aux pratiques de médiation", Esprit Critique, Vol.06, n. ${ }^{\circ} 3$, pp 17-29.

MENDES, Maria Manuel (2005), Nós os ciganos e os outros. Etnicidade e exclusão social, Lisboa, Livros Horizonte, 205 p.

MOSCOVICI, Serge; PEREZ, Juan António (1999), “A Extraordinária Resistência das Minorias à Pressão das Maiorias", Vala, Jorge (ed.), Novos Racismos, Lisboa, Celta, pp. 103-119.

NUNES, Olímpio (1981), O Povo Cigano, Porto, Livraria Apostolado da Imprensa.

OLIVEIRA, Ana, FREIRE, Isabel (2009), "Sobre...A Mediação Sócio-Cultural", Cadernos de Apoio À Formação, n. ${ }^{\circ} 3$, Lisboa, ACIDI.

OLIVEIRA, Ana e Galego, Carla (2005), A Mediação SócioCultural: um puzzle em construção, Observatório da Imigração, ACIME.

REMY, Jean (1998), Sociologie urbaine et rurale. L'espace el l'agir. Entretiens et textes preséntés par Étienne Leclercq, Paris, L'Harmattan.

RUS, Colin (2006), The situation of Roma School Mediators and Assistants in Europe, Directorate General IV, Directorate of School, Out-of-School and Higher Education Division of Educational Policies and European Dimension.

VITALE, Tomasso (2009), "Sociologia dos conflitos locais contra os Rom e Sinti em Itália. Pluralidade de contextos e variedade de instrumentos políticos", Cidades. Comunidades e Territórios, n. ${ }^{\circ}$ 19, Lisboa, Centro de Estudos Territoriais, pp. 65-80. 